\title{
To study the clinical correlation of headache and refractive error subtypes
}

\author{
Authors \\ Dr Supriya B N*, Dr Lokesh H M \\ Sri Siddhartha Medical College and Hospital, Agalakote, Tumkur \\ *Corresponding Author \\ Dr Supriya B N \\ Junior Resident, Department of Ophthalmology, SSMC, Tumkur
}

\begin{abstract}
Purpose: The prevalence of refractive errors is 13 to 80\%.The uncorrected refractive errors are associated with headache. Examination \& correction of defect will reduce headache. Minor refractive errors cause more headache \& symptoms than major refractive errors.

Material \& Methods: 150 patients with headache due to refractive error were included. A descriptive cross-sectional study. Subjects were evaluated like visual acuity, refraction, slit-lamp examination, retinoscopy were done. The type and amount of refractive error were estimated.

Results: Females (72\%) suffer more than males from headache. Refractive errors are more commonly associated with frontal headache (67\%). $82.7 \%$ of patients had a visual acuity $6 / 18$ and better. $43.6 \%$ of astigmatics, 33\% of hypermetropes presented with headache.

Conclusion: Most of the cases of astigmatism \& hypermetropia presents with headache than blurring of vision. Ciliary muscle contraction \& accommodation results in higher rate of headache in hypermetropes and astigmatics.
\end{abstract}

Keywords: Headache, Astigmatism, Hypermetropia.

\section{Background}

Headache and refractive errors are the common health problems in general population. The prevalence of refractive errors (RE) in the general population was reported to be from 13 to $80 \%$ based on variety of geographic areas and age group $^{1-3}$. Studies on ocular headache have reported the role of different ocular diseases like glaucoma, uveitis, optic neuritis, visual anomalies like refractive errors, accommodative and vergence deficiencies as the cause of headache. The uncorrected refractive errors are often associated with frontal and /or occipital headache ${ }^{4}$. A careful examination and possible correction of defect has been observed to reduce headache. Thomas.et.al noted that about $21 \%$ people with headache consult ophthalmologists for headache ${ }^{5}$. Whittington reported that among 1400 consecutive patients attending for refraction, $45 \%$ complained headache as a chief complaint ${ }^{6}$. Gordon.et.al claimed that minor refractive error often caused more headache and symptoms than major refractive error ${ }^{7}$. Ciliary muscle strain has also been found to be the possible cause of headache.

According to the International Headache Society (HIS), the criteria for the headache related to refractive errors are: 
(a) uncorrected refractive errors or miscorrected refractive errors;

(b) mild frontal pain as well as eye pain;

(c) pain that is relieved by resting but getting worse by doing visual tasks at the distance for a long time when visual acuity is impaired. $^{8}$

Though headache management is not easy always but it is often rewarding. The contribution of an ophthalmologist in the diagnosis and evaluation of a patient with headache is outlined. When asthenopia or an organic eye disease is the cause of the headache, ophthalmologist can not only diagnose the cause but also cure the patient by adequate therapy.

\section{Materials and Methods}

150 patients attending ophthalmology OPD at with headache due to refractive error were included in the study. A descriptive crosssectional study, was conducted after obtaining approval from Institutional Ethics Committee. Patients were enrolled for the study after written informed consent.

Such enrolled subjects underwent ophthalmic examinations including best corrected visual acuity with a Snellen chart at $6 \mathrm{~m}$, slit-lamp examination, cycloplegic refraction and retinoscopy were done. Refractive errors of both eyes were estimated using the retinoscopy and then refined with subjective refraction. The type of refractive error and amount of refractive error were estimated.

The data collected was entered in excel spread sheet. Descriptive statistical analysis was done by mean and standard deviation for quantitative variables and frequency and percentages for categorical variables. The association between categorical variables was analyzed by using Chi square test. The data was analyzed by using SPSS statistical software version 20 .

\section{Results}

The maximum incidence of headache $(43.3 \%)$ was found in the age group of 16-30 years, followed by in the age group of $31-45$ years $(31.3 \%)$. The incidence was the lowest $(10 \%)$ in the age group of less than 15 years [Table 1]. The incidence was higher in females $(72 \%)$ than males $(28 \%)$ [Table 2]. Students were found to be most commonly affected $(37.3 \%)$ followed by housewives (36\%), farmers $(10.7 \%)$, clerks $(3.3 \%)$, technical personnel (4\%), and others (10\%)[Table 3]. Chronic headache is more common (64\%)[Table 4].Frontal headache $(67.3 \%)$ is more common in refractive errors [Table 5]. The most common refractive error was astigmatism, which observed in $43.6 \%$ cases followed by hypermetropia (33\%) and presbyopia (20.1\%) [Table 6]. The most common type of astigmatism was mixed astigmatism (44.9\%), simple myopic astigmatism (37.2\%), compound myopic astigmatism (11.5\%), simple hypermetropic astigmatism $(6.4 \%)$ [Table 7]. Amount of refractive error less than $1 \mathrm{D}$ was detected in $69.3 \%$ cases, $23.3 \%$ cases between 1.25 and 2 D. Only $7.3 \%$ cases had more than 2 D of refractive error [Table 8]. Astigmatism lessthan $1 \mathrm{D}$ causes more headache and is significant in our study [Table 9].

Table 1 Age distribution of Headache

\begin{tabular}{|l|c|c|}
\hline Age & Frequency & Percent \\
\hline$<=15$ years & 15 & 10.0 \\
\hline $16-30$ & 65 & 43.3 \\
\hline $31-45$ & 47 & 31.3 \\
\hline$>45$ years & 23 & 15.3 \\
\hline Total & 150 & 100.0 \\
\hline
\end{tabular}

Table 2 Distribution of headache among two sexes

\begin{tabular}{|l|c|c|}
\hline Sex & Frequency & Percent \\
\hline Male & 42 & 28.0 \\
\hline Female & 108 & 72.0 \\
\hline Total & 150 & 100.0 \\
\hline
\end{tabular}

Table 3 Occupation of patients having headache due to ocular causes

\begin{tabular}{|l|c|c|}
\hline Occupation & Frequency & Percent \\
\hline Students & 56 & 37.3 \\
\hline Housewife & 54 & 36 \\
\hline Farmer & 16 & 10.7 \\
\hline Clerk, Tailor & 5 & 3.3 \\
\hline Technical Personnel & 4 & 2.7 \\
\hline Others & 15 & 10.0 \\
\hline Total & 150 & 100.0 \\
\hline
\end{tabular}


Table 4 Headache distribution based on duration

\begin{tabular}{|l|c|c|}
\hline Headache Duration & Frequency & Percent \\
\hline Acute & 13 & 8.7 \\
\hline Subacute & 41 & 27.3 \\
\hline Chronic & 96 & 64.0 \\
\hline Total & 150 & 100.0 \\
\hline
\end{tabular}

Table 5 Headache distribution based on region

\begin{tabular}{|l|c|c|}
\hline Headache Region & Frequency & Percent \\
\hline Frontal & 101 & 67.3 \\
\hline Occipital & 20 & 13.3 \\
\hline Combined & 29 & 19.3 \\
\hline Total & 150 & 100.0 \\
\hline
\end{tabular}

Table 6 Final diopteric correction of headache

\begin{tabular}{|l|c|c|}
\hline Diagnosis & Frequency & Percent \\
\hline Myopia & 2 & $1.1 \%$ \\
\hline Mixed & 4 & $2.2 \%$ \\
\hline Presbyopia & 36 & $20.1 \%$ \\
\hline Hypermetropia & 59 & $33.0 \%$ \\
\hline Astigmatism & 78 & $43.6 \%$ \\
\hline \multicolumn{2}{|c|}{$100.0 \%$} & $100.0 \%$ \\
\hline \multicolumn{2}{|l|}{ a. Dichotomy group tabulated at value 1. } \\
\hline
\end{tabular}

Table 7 Types of refractive errors causing headache

\begin{tabular}{|l|c|c|}
\hline ASTIGMATISM & Frequency & Percent \\
\hline Simple Myopic & 29 & 37.2 \\
\hline Compound Myopic & 9 & 11.5 \\
\hline Simple Hypermetropia & 5 & 6.4 \\
\hline Mixed & 35 & 44.9 \\
\hline Total & 78 & 100.0 \\
\hline
\end{tabular}

Table 8 Final diopteric correction of the refractive error

\begin{tabular}{|l|c|c|}
\hline Final Correction & Frequency & Percent \\
\hline$<1 \mathrm{D}$ & 104 & 69.3 \\
\hline $1.25-2 \mathrm{D}$ & 35 & 23.3 \\
\hline$>2 \mathrm{D}$ & 11 & 7.3 \\
\hline Total & 150 & 100.0 \\
\hline
\end{tabular}

Table 9 Amount of diopteric power in various type of astigmatism in headache

\begin{tabular}{|l|c|c|c|c|c|}
\hline \multirow{2}{*}{$\begin{array}{l}\text { FINAL } \\
\text { CORRECTION }\end{array}$} & \multicolumn{5}{|c|}{ Astigmatism } \\
\cline { 2 - 6 } & Simple Myopic & $\begin{array}{c}\text { Compound } \\
\text { Myopic }\end{array}$ & $\begin{array}{c}\text { Simple } \\
\text { Hypermetropia }\end{array}$ & Mixed & Total \\
\hline$<1 \mathrm{D}$ & $24(51.1 \%)$ & $3(6.4 \%)$ & $5(10.6 \%)$ & $15(31.9 \%)$ & $47(100.0 \%)$ \\
\hline $1.25-2 \mathrm{D}$ & $4(16.7 \%)$ & $2(8.3 \%)$ & $0(0.0 \%)$ & $18(75.0 \%)$ & $24(100.0 \%)$ \\
\hline$>2 \mathrm{D}$ & $1(14.3 \%)$ & $4(57.1 \%)$ & $0(0.0 \%)$ & $2(28.6 \%)$ & $7(100.0 \%)$ \\
\hline Total & $29(37.2 \%)$ & $9(11.5 \%)$ & $5(6.4 \%)$ & $35(44.9 \%)$ & $78(100.0 \%)$ \\
\hline Chi-Square value:30.379; P-Value: $<0.001$ & \\
\hline
\end{tabular}

\section{Discussion}

In our study, headache was found to be common in the age group of $16-30$ yeras $(43.3 \%)$. Shashi jain in their study also reported that maximum incidence in the age group of $15-30$ years $(46.8 \%))^{9}$ Headache in this particular age group can be due to stress caused by educational pressures, work stress, emotional factors and family conflicts .

In our study, headache was found to be higher in females $(72 \%)$ than in males. Similar findings are seen in other studies done by Shashi jain, Lanchner who reported incidence of headache in females to be $56.5 \%, 58.3 \%, 56 \%$, and $57 \%$ in their respective studies ${ }^{9,10}$. It can be due to the higher emotional instability, hormonal variation and psychological stress in females.
In our study headache due to ocular causes was mostly seen in students (37.2\%) followed by housewives (35\%). Shashi jain and Brown and Kronfeld also reported the similar results with $52 \%$ and $60 \%$ of student group having headache in their study. 9,11

In our study chronic headache was more common and was seen in $64 \%$ of the cases. Frontal headache was more common, seen in about $67.3 \%$ of the cases. Shashi jain in their study also reported that $67.7 \%$ of patients had anterior headache ${ }^{9}$. Ciliary pain is primarily frontal in origin as the ophthalmic division of trigeminal nerve is represented most caudally. ${ }^{12}$

In our study, the most common refractive error was astigmatism, which occurred in $43.6 \%$ cases followed by hypermetropia (33\%) . Shashi jain also reported that astigmatism $(42.37 \%)$ is the most 
common refractive error followed by hypermetropia (21.46\%)in causing headache ${ }^{9}$. Marasini also found that astigmatism was seen in $63.63 \%$, hypermetropia in $27.27 \%$, and myopia in $9.09 \%$ cases $^{13}$. Patwardhan and Sharma also claimed the same trend of refractive error prevalence in headache patients. ${ }^{14}$

Mechanism of headache in hypermetropia is from ciliary muscles contraction, where patients accommodate to see clearly and in astigmatism, especially in lower degree, where muscles contract irregularly which causes more severe headache.

In our study, there were $69.3 \%$ of patients with refractive error $<1 \mathrm{D}, 23.3 \%$ patients within 1.25 to 2 D. Similar observations were reported by Shashi jain, Griffith, who stressed that small astigmatism errors were responsible for more severe ocular asthenopia. ${ }^{9,15}$ Cogan also reported that small refractive errors, especially hypermetropia and astigmatism, causes headache. ${ }^{16}$

In our study it is significant with $\mathrm{p}$ value $<0.001$.

The reason for the higher incidence of headache in hypermetropic astigmatism and mixed astigmatism may be that involuntary, sustained excessive accommodative efforts put the eyes under strain.

\section{Conclusion}

Patients with astigmatism \& hypermetropia presents more commonly with headache than blurring of vision. Ciliary muscle contraction \& accommodation results in higher rate of headache in hypermetropes and astigmatics. A detailed clinical history, examination and proper correction of refractive error can help in relieving the headache and thereby improves the quality of life.

\section{Acknowledgement: Nil \\ Financial support: Nil}

\section{References}

1. Pan CW, Klein BE, Cotch MF, Shrager S, Klein R. Racial variations in the prevalence of refractive errors in the United States: the multi-ethnic study of atherosclerosis. Am J Ophthalmol. 2013; 155: 1129-1138.

2. Kempen JH, Mitchell P, Lee KE, Tielsch JM, Broman AT. The prevalence of refractive errors among adults in the United States, Western Europe, and Australia. Arch Ophthalmol. 2004; 122: 495-505.

3. Dandona R, Dandona L, Naduvilath TJ, Srinivas M, McCarty CA. Refractive errors in an urban population in southern India: the Andhra Pradesh Eye Disease Study. Invest Ophthalmol Vis Sci. 1999; 40: 2810-2818.

4. Bellows JG. Headache and the eye.Headache. $1968 ; 7: 165---170$.

5. Thomas E, Boardman HF, Ogden H, Millson DS, Croft PR.A dvice And care for headaches: who seeks it, who gives it?Cephalalgia.2004;24:740---752.

6. WhittingtonTD. The art of clinical refraction.London:Oxford University Press; 1958.

7. Gordon DM. Some Headaches in an ophthalmologist's office. Headache. 1966;6:141---146.

8. Classification and diagnostic criteria for headache disorders, cranial neuralgias and facial pain. Headache Classification Committee of the International Headache Society. Cephalalgia. 1988; 8: 1-96.

9. Jain S, Chandravanshi SL, Dukariya L, Tirkey ER, Jain SC. Clinical study of headache with special reference to ophthalmic cause. Int J Med Sci Public Health 2015;4:292-7.

10. Lanchner AJ. Headache in ophthalmic practice. Neurology 1952;2:471-6.

11. Brown EVL, Kronfeld PC. The acuity of binocular depth perception in hemianopsia.Trans Am Ophthalmol Soc 1930; 28:231-49.

12. Blehm C, Vishnu S, Khattak A, Mitra S, Yee RW. Computer vision syndrome: a review. Surv Ophthalmol 2005; 50: 253-62 
13. Marasini S, Khadka J, Sthapit PRK, Sharma R, Prasad B. Ocular morbidity on headache ruled out of systemic causes- a prevalence study carried out at a community based hospital in Nepal. Nepal J Optom 2012;5:68-74.

14. Patwardhan SD, Sharma P, Saxena R, Khanduja SK. Preferred clinical practice in convergence insufficiency in India: a survey. Ind J Ophthalmol. 2008;56:303--306.

15. Griffith A. The eyes as a cause of headache. Br Med J 1934;2:296-7.

16. Cogan DG. Popular misconceptions pertaining to ophthalmology. New Engl J Med 1941;224:462-6. 